\title{
Turismo, Patrimonio y Centros Historicos. Estrategias de marketing cultural en la ciudad de Málaga.
}

\section{Tourism, Heritage and Historical Centers. Cultural marketing strategies in the City of Málaga}

\author{
LOURDES ROYO NARANJO \\ Profesora Departamento de Historia, Teoría y Composición Arquitectónica. \\ ETSAS, Universidad de Sevilla (España)
}

lroyo@us.es

Recibido: $22 / 07 / 2017$

Aceptado: 27/09/2017

\section{Resumen}

Hoy en día, la recuperación de los centros históricos se ha convertido en una referencia clave para estimular el turismo y el desarrollo de este sector gracias a la demanda de una industria concebida como motor económico y fuente de riqueza. En concreto, Málaga, se ha convertido en un reclamo cultural y turistico a escala internacional, cuyos efectos en la ciudad están repercutiendo en su patrimonio histórico y urbano, más allá de los esperados y aparentes beneficios económicos. Málaga ha logrado en una década estar entre los destinos turísticos culturales más importantes del mundo gracias a un fuerte empuje político y un proyecto que lidera la marca "Málaga Ciudad de Museos". Proponemos en el siguiente artículo, un análisis y revisión de las principales acciones que responden a la recuperación financiera de esta ciudad aprovechando un factor de gran importancia como es el turismo cultural, dado que Málaga ejerce la capital turística de la Costa del Sol y, sobre todo, directo y potencialmente un impacto en el aumento de la actividad económica. 


\title{
Palabras clave
}

Turismo, patrimonio cultural, centros históricos, Málaga, márketing cultural, Museos.

\begin{abstract}
Nowadays, the recovery of historic centers has become a key reference to stimulate tourism and the development of this sector thanks to the demand for a sector designed as an economic engine and source of wealth. Málaga, has become a cultural and tourist attraction on an international scale, whose effects on the city are impacting on its historical and urban heritage, beyond the expected and apparent economic benefits. Málaga has achieved in a decade to be among the most important cultural tourism destinations in the world thanks to a strong political push and a project that leads the brand "Malaga City Museums". We propose the following communication analysis of the main actions that respond to the financial recovery of this space city taking advantage of a factor of great importance as it is tourism, given that exerts Málaga tourist capital of the Costa del Sol, and most importantly, direct and potentially impact on the increase in economic activity.
\end{abstract}

\section{Keywords}

Tourism, cultural heritage, historical centers, Málaga, Cultural Márketing, Museums.

Referencia normalizada: ROYO NARANJO, LOURDES (2017): "Turismo, Patrimonio y Centros Históricos. Estrategias de márketing cultural en la ciudad de Málaga". Arte y Ciudad. Revista de Investigación, no 12 (octubre), págs. 211-224. Madrid. Grupo de Investigación Arte, Arquitectura y Comunicación en la Ciudad Contemporánea, Universidad Complutense de Madrid.

Sumario: 1. Introducción. 2. Patrimonio y Paisaje Urbano. 3. La ciudad histórica como destino. 4. Turismo de masas y centros históricos. Nuevas estrategias de márketing cultural. 5. Málaga ciudad de Museos. El posicionamiento de Málaga a escala internacional en turismo cultural. 6. Los conflictos derivados del proceso de "turistificación" en el centro histórico de Málaga. 7. Conclusiones. 8. Bibliografía. 


\section{Introducción.}

El turismo masivo en los centros históricos no es en absoluto un tema de reciente actualidad, sin embargo, la intensidad de turistas que diariamente reciben las ciudades históricas y sus monumentos, sí llega a ser una cuestión de enorme interés para la conservación y gestión del patrimonio. El desbordamiento de la capacidad de acogida de los destinos patrimoniales ocasiona daños irreparables a unos recursos culturales convertidos en base de la actividad turística actual (Troitiño, 2016). Como consecuencia, la profusión de documentos e investigaciones que sobre este debate se han efectuado en las últimas décadas obedece, entre otras cuestiones, a un cambio en el modelo turístico y a la gestión de sus recursos. Un modelo diseñado de manera que en los centros históricos se concentran los problemas propios de cualquier aglomeración urbana pero elevados a una categoría en la que es fácil detectar conflictos y tensiones como consecuencia de la concentración de actividades terciarias en algunas zonas frente a la inexistencia en otras o el envejecimiento de la población y el agotamiento de un patrimonio cultural extremadamente frágil.

Una nueva situación que posiciona a las ciudades ante nuevos usos y su reconocimiento en un espacio urbano que se transforma para cumplir objetivos culturales y turísticos asociados al mismo tiempo a los valores de la ciudad histórica. Sin embargo, la delgada y delicada línea que separa el disfrute turístico y por ende aquellos efectos positivos recibidos de tal actividad, también generan una serie de cuestiones oscuras y negativas asociadas esta vez a fenómenos como la turistización del patrimonio. En este panorama de reciente actualidad, la ciudad histórica de Málaga se convierte en un claro ejemplo al que acudir como caso de estudio para entender un fenómeno que arranca con la creación e invento como destino cultural con marca propia y que empieza a recoger sus frutos.

\section{Patrimonio y Paisaje Urbano.}

La primera vez que se habla del cuidado del paisaje histórico en las ciudades será en la Carta de Venecia de 1964, mientras que en la Carta de Quito de 1967', se expondrá la necesidad de conciliar las exigencias del progreso urbano con la salvaguarda de los valores ambientales. Según el Convenio Europeo del Paisaje 2000, suscrito por España en 2007, se define como Paisaje "cualquier parte del

\footnotetext{
${ }^{1}$ Conservación y Utilización de Monumentos y Lugares de Interés Histórico y Artístico. Quito, 1967.
} 
territorio tal como lo percibe la población, cuyo carácter sea el resultado de la acción e interacción de factores naturales y/o humanos". A su vez, se distingue entre medidas de "protección, gestión y ordenación paisajística". Por otra parte, el Memorándum de Viena de 2005 extiende el marco patrimonial al "paisaje urbano", entendido más allá de los tradicionales "centro histórico", "conjunto" o "entorno" y reclama un compromiso de "complementariedad" para la nueva arquitectura en relación a la naturaleza histórica de la ciudad.

Con todo, tanto las directrices del Memorándum de Viena, la Carta de Zacatecas y otros documentos internacionales recientes, el Paisaje Histórico Urbano "supera la idea del edificio en sí, para considerar el lugar, el perfil de la ciudad, los ejes visuales, las líneas y tipos de edificios, los espacios abiertos, la topografía, la vegetación y todas las infraestructuras" (Rivera, 2013). De este modo, el patrimonio de nuestras ciudades y en concreto el de los centros históricos, no puede quedar restringido a la mera consecución de varios elementos seleccionados de manera aislada y ensalzados de forma caprichosa como baluarte, pues todos ellos obedecen a una lógica histórica y cultural que definen de manera mucho más compleja, más plural y al mismo tiempo frágil, el valor de ese Patrimonio Cultural cuya carga de identidad es lo que realmente lo hace único.

\section{La ciudad histórica como destino.}

No podemos hablar propiamente de turismo como actividad y fenómeno social hasta finales del Antigo Régimen, pues una de las características más importantes que asociaremos a los desplazamientos turísticos será la cuestión del ocio y la consideración del tiempo de disfrute (Royo, 2013). De esta forma, será el Grand Tour el primer antecedente de los viajes turísticos actuales (Grande, 2001; Moreno, 2007; Valls, 2003) y la primera mitad del siglo XX cuando se creen los primeros turoperadores. En estos momentos, las ciudades y sus monumentos se convierten en los destinos solicitados, con una intención prioritaria de conocimiento cultural que poco a poco dejará paso a las primeras estaciones balnearias y destinos de sol y playa. En la segunda mitad del siglo $\mathrm{XX}$, el cada vez más incipiente turismo de sol y playa derivará en una pérdida de protagonismo de las ciudades como destino. El litoral y sus entonces bondades, eclipsará cualquier otro atractivo para el turista moderno, con la llegada de un período de reconstrucción y crecimiento económico a nivel nacional que llegará hasta los años ochenta. Desde entonces hasta hoy, 
las ciudades monumentales han ido adquiriendo, cada vez más, un mayor protagonismo, hasta el punto de ser el destino por excelencia de la cadena turística mundial. Impulsado por el turismo, el patrimonio de las ciudades monumentales trasciende su dimensión cultural, como legado histórico y memoria colectiva, y se transforma en recurso productivo (Calle \& García, 1998). Recurso hacia el que muchas ciudades orientan sus programas e inversiones en un sobreesfuerzo cada vez mayor por rentabilizar su patrimonio, convertido así en protagonsita principal y generador de recursos turísticos y económicos. En esta tesitura, el patrimonio de las ciudades, portador de dimensiones o funciones de naturaleza diversa, cultural, social, simbólicas..., adquiere a partir de la introducción del turismo un gran valor como producto. Circunstancia manifiesta a partir de la Carta de Bruselas de 2009, donde la consideración económica de la cultura ha propiciado una valoración de la ciudad como un bien y como un factor más de desarrollo territorial. (Morate, 2013), pues retomando el hilo argumental, el patrimonio de nuestras ciudades no sólo es importante por su valor histórico y por ser soporte de la identidad de los pueblos, sino como un recurso de desarrollo.

\section{Turismo de masas y centros históricos. Nuevas estrategias de márketing cultural.}

Considerable es el volúmen de aportaciones a la literatura científica sobre este tema (Catro, 2005; De Esteban, 2008; Martos, 2016; Toselli, 2006; Velasco, 2009 ) que marcan la atención en torno a los aspectos positivos y negativos del uso y abuso turístico del patrimonio cultural en las ciudades históricas. En realidad, la ciudad turística se concentra en una parte bastante pequeña de la ciudad histórica y en su configuración influyen factores de naturaleza diversa: históricos, promocionales, simbólicos, urbanísticos, etcétera (Calle, 2002). Aunque se percibe un avance en la valorización e interpretación del patrimonio cultural como recurso turístico, existen serias dificultades para adecuar los centros históricos a la función turística, pues qué duda cabe que la ciudad turística es una parte de la ciudad histórica no siempre bien gestionada, pero estrechamente conectada entre los circuitos de carácter turístico y los grandes hitos de referencia cultural. Tal es así que una de las mayores oportunidades que el turismo ofrece a los centros históricos es la recuperación y puesta en valor de un patrimonio urbanístico (Troitiño, 2009). 
Nuevas situaciones ante las que debemos buscar cierto equilibrio con el fin de evitar los conflictos que se suelen plantear entre el turismo y la conservación del patrimonio, en este caso de los centros históricos. Su mantenimiento constituye un reto para su pervivencia como realidad social, aunque detectamos sin embargo, cómo tales cuestiones no están resultando nada fácil poner en marcha en tanto en cuanto, las políticas integradas de recuperación, más allá de las dimensiones arquitectónicas, deberían afrontar en profundidad cuestiones funcionales y sociales con el fin de evitar convertir los centros históricos en meros decorados urbanos o grandes museos abiertos.

Este redescubrimiento de los centros históricos y su relación con el turismo cultural, ha provocado como consecuencia un nuevo énfasis en las políticas de regeneración y rehabilitación de los mismos, así como la búsqueda de fuentes específicas para su financiación, en paralelo a una recuperación patrimonial que de manera evidente refuerza la imagen y la identidad del destino, intentando establecer una diferenciación como marca patrimonial. Cobran especial importancia en este contexto los Fondos Europeos de Desarrollo Regional (FEDER), que a lo largo de dos décadas han proporcionado recursos económicos a regiones europeas especialmente débiles entre las que ha destacado Andalucía y, más concretamente, los centros históricos de sus ciudades.

Es aquí donde atendemos a la aparición de la estrategia de marketing cultural que ya mencionaba Richards (2006), aplicada de forma directa para el beneficio de la industria del turismo de modo que patrimonio urbano, cultura e imagen se unen para ofrecer un producto completo, atractivo e inequívocamente focalizado hacia la difusión de una interpretación muy concreta de la realidad patrimonial de los centros históricos considerados. Es entonces, cuando el sector cultural se ve abocado a renovar los antiguos modelos de gestión cultural, en busca de una integración de la profesionalización y la orientación empresarial, con un esfuerzo por no perder la identidad en su discurso patrimonial renovado, que busca y prioriza objetivos económicos y por tanto el retorno de la inversión pública y privada.

El marketing aplicado a la cultura o marketing cultural, se presenta entonces como herramienta de gestión empresarial necesaria e imprescindible para el diseño de nuevas estrategias y políticas de promoción, comercialización, difusión y comunicación. En este nuevo escenario, el turista aparece como 
gran consumidor de bienes y servicios culturales y su presencia dinamiza los diversos sectores de actividad que generan riqueza y empleo, al mismo tiempo que introduce nuevas modalidades en el consumo y en el uso de las ciudades, desarrollando ramas como la hostelería, restauración, transporte, comercio, servicios de ocio o recreo, así como otros sectores de actividad en un segundo orden orientados al turista.

\section{5. "Málaga ciudad de Museos". El posicionamiento de Málaga a escala in- ternacional en turismo cultural.}

Los trabajos del I PEM ${ }^{2}$ arrancan en el año 1992 con un escenario tendencial donde Málaga no es reconocida como capital de la Costa del Sol y los congresos se celebran en municipios limítrofes por falta de equipamientos. Como principales objetivos se marca un desarrollo del litoral, la recuperación del legado histórico y monumental de la ciudad junto con el desarrollo de nuevos segmentos turísticos (congreso, cultural, deportivo, etc...) capaces de mejorar el atractivo de Málaga en un deseado mercado internacional. Se piensa entonces en la construcción de un programa capaz de convertir a Málaga en "capital turística, cultural y de ocio europeo" y se creará, para sumar esfuerzos en ese sentido, la Delegación de Turismo en el Ayuntamiento de Málaga como una nueva Concejalía específica para ello. Tal y como se recoge en el Documento de Evaluación del I Plan Estratégico de Málaga, tras la finalización de este I Plan Estratégico "Málaga mejora su posición competitiva en el mercado regional y nacional, pero sigue necesitando una imagen de ciudad sólida que le reafirme con ventaja en los mercados europeo e internacional. Necesita mejorar tanto en las condiciones turísticas y culturales como en la coordinación de su oferta"3. En esta misma línea de trabajo aparece el Plan de Desarrollo Turístico de la Ciudad de Málaga de 1996 en una clara apuesta por el desarrollo del turismo cultural de la ciudad. En el 2002 se inicia verdaderamente el II Plan Estratégico de Málaga ${ }^{4}$ que tiene su continuidad hasta el 2004. Durante estos años, diversos informes irán acompañando al proceso y aparecerán publicados algunos de los resultados esperados, necesidades detectadas o me-

\footnotetext{
2 Plan Estratégico de Málaga (1993- 1996). Málaga en la Costa del Sol.

${ }^{3}$ Fuente I Plan Estratégico de Málaga: http://www.ciedes.es/ [Última consulta el 15/05/2015]

${ }^{4}$ II Plan Estratégico de Málaga (2000- 2004). Málaga "metrópoli abierta".
} 
morias de trabajo de diversa índole ${ }^{5}$. Entre estos, cabe destacar el informe publicado como material de trabajo previo a la redacción del II Plan Estratégico en el que se descubren algunas de las claves estratégicas más interesantes en cuanto a turismo y cultura se refiere. Así, en el Análisis de la evolución de la ciudad, se concentran algunos de los "Retos de Economía" más importantes en los que la cultura aparece convertida ya en motor principal del desarrollo tan esperado y perseguido.

El posicionamiento de Málaga a escala internacional como un destino de turismo urbano cultural y la cultura como fuente de riqueza y empleo de calidad destaca entre algunos de los principales objetivos marcados diferente "Retos de Territorio y Medio Ambiente" como la consolidación del proceso de revitalización del Centro Histórico de Málaga y la consolidación de Málaga como capital de la Costa del Sol. De manera resumida, el II Plan Estratégico de Málaga propone 4 líneas estratégicas y 10 proyectos estrella: "Una Metrópoli que mira al mar", "La Málaga de Picasso, cultural y atractiva”, "Una metrópoli en la vanguardia de la sociedad del conocimiento" y "Una ciudad renovada para sus ciudadanos y visitantes". A su vez, éstas líneas estratégicas se organizan según 4 visiones de Málaga con sus consiguientes proyectos: "Málaga ciudad litoral", "Málaga ciudad de la cultura", "Málaga ciudad del conocimiento" y "Málaga revitalización urbana" (Royo, 2015).

Dentro del binomio que une a Málaga y su cultura como elementos capaces de dinamizar la economía y convertirse en motor de desarrollo ampliando su espectro al turismo como principal factor, llama la atención el enorme esfuerzo político realizado durante estos años, así como el ingente interés por llevar a cabo la línea estratégica "La Málaga de Picasso, cultural y atractiva". Entre los Proyectos Estrella más importantes que se recogen destaca el Ágora Mediterráneo. La ciudad como espacio de cultura, en referencia a la dotación y recuperación de espacios públicos de encuentro y convivencia ciudadana, la consolidación del proceso de revitalización del Centro Histórico de Málaga, la

\footnotetext{
${ }^{5}$ Entre los informes más destacados podemos contar con la Evaluación del II Plan Estratégico de Málaga; Transformando Málaga. 1994-201; Nuevos Rumbos. Reflexiones del II PEM para el 2020; Málaga, Metrópoli Abierta". II Plan Estratégico de Málaga; Málaga Metrópoli Abierta - Avance de Proyectos Estrella del II Plan Estratégico de Málaga o La Aventura de diseñar el propio destino. Plan Estratégico de Málaga, todos ellos editados por la Fundación CIEDES y consultables en http://www.ciedes.es/ [Última consulta el 15/05/2015]
} 
cultura como fuente de riqueza y empleo, y la reforma del espacio urbano para potenciar el atractivo de la historia y la cultura malagueña. Como consecuencia de todo lo anterior, el centro histórico de Málaga no se ha convertido en un espacio privilegiado, sino en un invento cultural que nace de manera oficial bajo la definición de Megamuseo cuya marca Málaga Ciudad de Museos. Donde habita el arte, es el máximo reflejo de una muy definida apuesta cultural $\mathrm{y}$ artística a nivel internacional.

Con un abanico de 37 museos y centros expositivos, la oferta cultural presente en la ciudad de Málaga se concentra en una oferta museística en la actualidad la más competitiva a nivel nacional. De hecho, Málaga es el cuarto destino de España en número de visitas recibidas, más de 850.000 el pasado año. La capital registra 81,4 visitas a los museos por cada cien pernoctaciones, por delante de destinos como Valencia, Madrid, Barcelona o Sevilla, y representados por espacios culturales como el Centre Pompidou, el Centro de Arte Contemporáneo CAC Málaga, el Museo de Málaga en el Palacio de la Aduana, el Museo Picasso, la Colección del Museo Ruso o el Museo Automovilístico y de la Moda, todos ellos iconizados como parte del skyline cultural que dibuja Málaga. Una ciudad que vende cultura y se autoproclama como referente cultural.

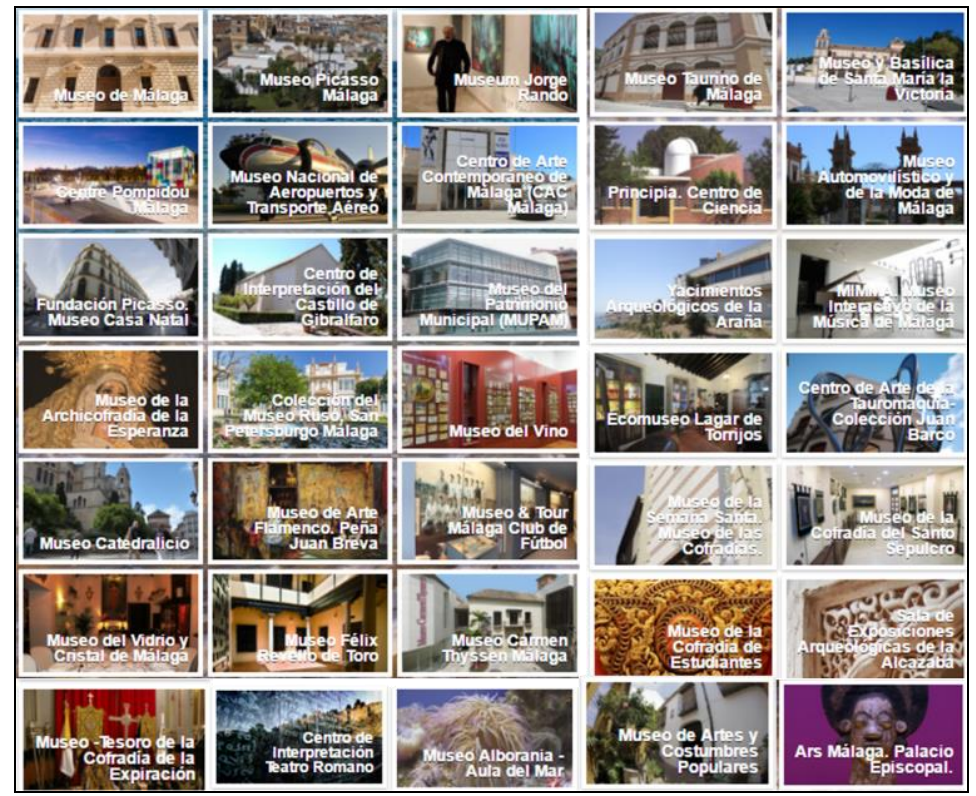

Figura 1. Museos de Málaga. Itinerarios propuestos 2016. 


\section{Los conflictos derivados del proceso de "turistización" en el centro histórico de Málaga.}

De manera teórica sabemos que los centros históricos se caracterizan por ser espacios intensamente vividos por sus ciudadanos con carácter multifuncional, dada la gran diversidad de actividades que en ellos conviven, así como por la heterogeneidad que presentan a nivel social, fruto de las continuas transformaciones de la propia ciudad a lo largo del tiempo y los valores culturales asociados (Troitiño, 1995). Cualidades que a propósito de nuestro caso de estudio están desapareciendo como consecuencia de un fuerte proceso de turistización en el que se ve inmerso su centro histórico y cuyos efectos más visibles han afectado a la economía local, al medio ambiente, al paisaje urbano y, sobre todo, a la vida cotidiana, estando estos impactos turísticos estrechamente ligados al volumen de la afluencia de visitantes fruto del crecimiento del turismo masivo (Royo, 2016) y a la gestión de dichas actividades.

La característica fundamental que evidencia un problema de crisis de convivencia con la actividad turística es la desaparición de la vida residencial, el progresivo abandono de las viviendas del entorno, pues la presión del turismo una vez superados ciertos límites puede incitar, en el caso de los centros históricos, a que la población residente los abandone, provocando procesos de des-

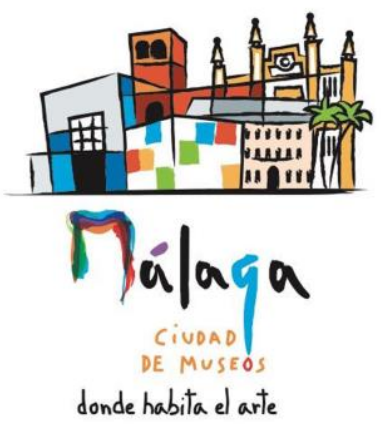

Figura 2. Logo Ciudad de los Museos. Málaga, 2017. población, rupturas de equilibrio social y desapego patrimonial (Trotiño Vinuesa y Troitiño Torralba, 2010). Un hecho motivado por los continuos cambios de uso de los edificios que se rehabilitan para uso hotelero, la falta de comercios de abastecimiento primario en la zona y la dificultad de accesibilidad y tránsito consecuencia del elevado flujo turístico. Un tejido social heterogéneo que se va deteriorando progresivamente, disminuyendo la población vecinal a favor del visitante-espectador y consumista temporal. De este modo, la vida del barrio es suplantada por "escenarios" teatralizados diseñados para el turista-consumidor con los que el ciudadano malagueño no se identifica. Un proceso acompañado inevitablemente de una pérdida de la calidad, ya no sólo en la vida diaria del residente, sino para el propio turista que ni siquiera podrá disfrutar de la expe- 
riencia, ya que la estructura física de la calle no tiene suficiente capacidad para acoger el elevado número de peatones, coches, autobuses, bicicletas y segways que tienen que compartir este espacio tan limitado en algunos tramos del centro histórico de Málaga.

Todas estas condiciones han dado lugar a la proliferación de un "turismo basura" generado por la gestión cortoplacista y desequilibrada de las Administraciones que siguen priorizando la explotación turística de este entorno en lugar de promover sus posibilidades culturales, lo cual potenciaría la recuperación del patrimonio y su uso colectivo, ya que el reforzamiento de la dimensión cultural del centro histórico está en la base de la formulación de las políticas de recuperación, entendidas en el sentido de una búsqueda de nuevos equilibrios entre las realidades físicas, las sociales y las funcionales (Troitiño, 2003).

\section{Conclusiones.}

Málaga es un destino turístico reconocido, aunque su capacidad de atracción quedó diluida en las últimas décadas del siglo XX por la creciente pujanza de la Costa del Sol. Como consecuencia de ello el planeamiento estratégico resolvería en los los años ‘90 gran parte de las carencias detectadas, en un esfuerzo por recuperar no sólo la centralidad internacional sino en un segundo nivel, la posición de una ciudad como referencia del turismo cultural urbano. En este sentido, la planificación estratégica aporta al urbanismo y al turismo nuevas perspectivas que permiten, además, trasladar los designios actuales de las políticas urbanas globales a la escala local. Desde el punto de vista de las estrategias urbanas, la ciudad debe ser capaz de plantear en sus centros históricos estrategias de integración complementarias a la dimensión turística, pues es la multifuncionalidad uno de los rasgos que otorga identidad propia a los centros históricos. Nuestros centros históricos tienen que lograr la reutilización funcional de su rico y diversificado patrimonio cultural, (Troitiño, 2003) atendiendo de manera individualizada en el momento de formular y gestionar las políticas de protección y recuperación a la singularidad de cada centro histórico y su dinámica interna.

De cara a la implementación o gestión de estrategias de promoción turística en el centro histórico, se vuelve necesario el establecimiento de una estrategia integrada que contemple los efectos positivos y negativos de las actuaciones previstas a largo plazo, pues resulta un paso fundamental como garan- 
tía del éxito futuro. Así, como logros de la Planificación Estratégica y mecanismos de márketing cultural estudiados y actualmente en proceso de revisión de 20 años de trabajo en el centro histórico de Málaga, advertimos algunos resultados que desglosamos a continuación:

- Existencia de un modelo de ciudad creado con el que competir internacionalmente.

- Un crecimiento de la ciudad de Málaga como destino turístico que ha sido posible gracias al diseño y ejecución de un planeamiento estratégico encaminado a la construcción de un discurso en el que patrimonio cultural y turismo como recurso económico se dan la mano.

- La recuperación del centro histórico de Málaga es un gran vacío en la política cultural de Málaga, cuya puesta en valor de su patrimonio cultural se ha centrado exclusivamente en la creación de nuevos espacios culturales entre los que merece una especial mención el Museo Picasso de Málaga, el Centro de Arte Contemporáneo o el Centro Pompidou, y que si bien confieren a Málaga un gran atractivo cultural y turístico que la diferencia del resto de ciudades, la convierten en una ciudad sin identidad propia y sin historia.

- El incremento del turismo y los esfuerzos por mantener a este sector sobre un mismo escenario o centro histórico de Málaga conlleva, no sólo grandes ventajas de desarrollo socioeconómico, sino serios riesgos que hacen peligrar la autenticidad del mismo.

- Creemos necesario establecer unas cautelas previas en las que se determinen según criterios históricos y patrimoniales qué espacios de la ciudad histórica son susceptibles de convertirse o adaptarse a los recorridos turísticos y cuáles no, reforzando el protagonismo de Málaga como ciudad de referencia del turismo cultural urbano.

\section{Bibliografía.}

CAlle, M. y GarcíA, M., (1998): “Ciudades históricas, patrimonio cultural y recurso turístico", Ería, 47, 249-266.

CAlle, M. (2002): La ciudad histórica como destino turístico. Barcelona: Ariel. 
CATRO, J.F. (2005): “La calidad como herramienta de gestión del turismo cultural", Pasos, 3, 143-148.

DE EstebAN, J., (2008): Turismo cultura y medio ambiente en destinos urbanos, Servicio de Publicaciones de la Universidad Rey Juan Carlos, Madrid.

GRANDE, J. (2001): Análisis de la oferta de turismo cultural en España. Estudios Turísticos, 150, pp.15-24.

MARTOS, M. (2016): Herramientas para la gestión turística del patrimonio cultural, Trea Ediciones, Madrid.

MORATE, G. (2013):" La economía sin ambages en la gestión del patrimonio", Revista PH. Instituto Andaluz de Patrimonio Histórico, no 84, Sevilla, 2013.

MORENO, A. (2007): Historia del turismo en España en el siglo XX, Síntesis, Madrid.

RICHARDS, (2006): “Developing Creativity in Tourist Experiences: A solutions to Serial Reproduction of Culture", Tourism Management, 27 (6), p. 12091223.

Rivera Blanco, J. (2013): "La Carta de Cracovia y otros Documentos Contemporáneos: Su aplicación en la ciudad", Encuentro Internacional de Arquitectura Contemporánea en Ciudades Históricas, Sevilla 17-19 Septiembre.

ROYO NARANJO, L. (2013): Turismo, desarrollo, arquitectura. La aventura de la modernidad, Junta de Andalucía, Sevilla.

(2015): “Recuperación de centros históricos: Málaga, capital del turismo cultural urbano del S.XXI", VIII Jornadas Investigación en Turismo, Universidad de Sevilla, Sevilla.

_ y Armenta, C. (2016): “La turistización de los centros históricos y su protección patrimonial, el caso de la Carrera del Darro de Granada, IV Convegno Internazionale sulla documentazione, conservazione e recupero del patrimonio architettonico e sulla tutela paesaggistica, Pavía .

RUBIO FlORIDO, A. (1996): “Del planeamiento clásico al planeamiento estratégico: el núcleo histórico de la ciudad de Málaga", II Jornadas de Geografía urbana: Recuperación de centros históricos, utopía, negocio o necesidad social, Universidad de Alicante, Secretariado de Publicaciones, Alicante, pp. 201-207.

TOSELLI, C. (2006): Algunas reflexiones sobre el turismo cultural. Pasos, 4(2), 175-182. 
TROITIÑO, M. A. (2003): La protección, recuperación y revitalización funcional de los centros históricos. Mediterráneo Económico, 3, col. Ciudades, arquitectura y espacio urbano, 131-159.

(2005): "Potencialidades y límites en el uso turístico del patrimonio cultural" en Instituto de Turismo Responsable. Forum Mundial de las Culturas Diálogo sobre Turismo, Diversidad Cultural y Desarrollo Sostenible. Barcelona, pp. 83-88.

(2009): “Turismo cultural y destinos patrimoniales en España: situación actual y retos de futuro", en MONDÉJAR, J.A. y GóMEZ, M.A., Turismo cultural en ciudades Patrimonio de la Humanidad. Universidad de Castilla-La Mancha.

(2010): "Patrimonio y Turismo: una complementariedad necesaria en un contexto de uso responsable del patrimonio y cualificación de la visita". Patrimonio Cultural de España, 3, 89-108.

_ (2016): "Patrimonio y turismo: reflexión teórico-conceptual y una propuesta metodológica integradora aplicada al municipio de Carmona (Sevilla-España)", Scripta Nova, Universidad de Barcelona.

VALLS, J.F. (2003): Las claves del mercado turístico. Cómo competir en el nuevo entorno. Bilbao: Deusto.

VELASCO, M. (2009): Gestión turística del patrimonio cultural: enfoques para un desarrollo sostenible del turismo cultural. Cuadernos de Turismo, Murcia, 23, 237-253. 